\title{
Introduction: Political Implications of Moral Enhancement
}

\author{
Norbert Paulo • Christoph Bublitz
}

Received: 23 December 2017 / Accepted: 27 December 2017 /Published online: 13 January 2018

(C) Springer Science+Business Media B.V., part of Springer Nature 2018

Even after a decade of debate, the promises and perils of moral enhancements still attract considerable interest in academia and beyond. While much has been written and said about a range of pertinent issues, from empirical feasibility to conceptual issues to the "freedom to fall", the aim of the papers collected in this special issue is to emphasize a somewhat neglected problem, namely the political dimension of moral enhancement. JeanJacques Rousseau famously declared in the very first sentence of his The Social Contract that the task of political philosophy is "to inquire whether, taking men as they are and laws as they can be made to be, it is possible to establish some just and reliable rule of administration in civil affairs" ([1], 155, italics added). The highlighted passage reflects the assumption that politics may change the prescriptive and contingent laws of the state in order to fit the more or less constant anthropological properties of humankind. However, social orders have always striven to enhance the moral behaviour of

\footnotetext{
N. Paulo $(\bowtie)$

Institute of Philosophy, University of Graz, Attemsgasse 25, 8010 Graz, Austria

e-mail: norbert.paulo@sbg.ac.at

N. Paulo

Department of Social Sciences and Economics, University of

Salzburg, Churfürststr. 1, 5020 Salzburg, Austria

C. Bublitz

Faculty of Law, University of Hamburg, Rothenbaumchaussee 33, 20148 Hamburg, Germany
}

their members to promote social cooperation and to ensure security. Education, moral, legal or religious systems and psychiatric institutions are example of traditional ways of influencing moral behaviour for the better. Already Aristotle noted, "the true politician ... wants to make citizens good and obedient to the laws" ([2], 20 [1102a8-10]). And Rousseau's educational works are prime examples of traditional ways to make people morally better. This tension between the contingent and the constant, which has implications for the proper place of political intervention, is shifting. Human properties once conceived as hardly alterable have become the object of scientific experimentation. It seems moral behaviour, moral thought and moral emotions can be manipulated through non-traditional means, at least in the lab. That is, humankind's constant anthropological properties might turn out to be alterable.

Conversely, answers to questions about politics usually emphasize their relative and contingent nature. However, there seems to be a slowly emerging shared belief in the paramount importance of some political goals: The fight against anthropogenic climate change and global warming, the alleviation of global injustice, and minimizing the threat of weapons of mass destruction, to name some of the most obvious. Of course there is disagreement about these matters even in the highest places of political power, but we cannot but share the hunch, forcefully expressed by Ingmar Persson and Julian Savulescu, that there are no good reasons to doubt the importance of these goals as a matter of public policy. That is, these political goals no longer seem to be contingent. Persson and Savulescu's book Unfit for 
the Future (2014) contains many political claims, and their proposals sometimes resemble a reversal of Rousseau's opening statement. The new task of political philosophy might be to take laws as they are and (wo!-)men as they can be made to be. But what does this new approach imply on the level of the political? For instance, what does it mean for the relation between states, governments and the common good on the one hand and the minds of individual citizens on the other? Should the use of biomedical moral enhancements be permissible (for instance, $[3,4]$ ), or are they, from the perspective of the common good, merely desirable (e.g., [5])? Still others argue that it is imperative to pursue the development of such enhancements, leaving open how they should be administered [6-8]. These questions already bring us to the papers in this issue, all of which deal with the implications moral enhancement might have in the political sphere.

In "The Tragedy of Biomedical Moral Enhancement," Stefan Schlag investigates whether the merely voluntary use of enhancers is apt to solve the megaproblems of humanity, such as anthropogenic climate change. More concretely, he scrutinizes a central argument in Unfit for the Future, the tragedy of the commons. Schlag applies the tragedy of the commons argument to the context of moral enhancement and argues that Persson and Savuescu's argument is, in fact, selfdefeating because the implementation of moral enhancement policies would face similar collective action problems as the prevention of climate disaster.

In their response to Schlag's paper ("Biomedical Moral Enhancement - not a Lever without a Fulcrum"), Persson and Savulescu take issue with the claim that the implementation of moral enhancement policies would face collective action problems similar to those present in climate change prevention. To this end they invoke the importance of another level of moral enhancement than the one Schlag is concerned with. Schlag's argument plays out at the level of moral behaviour. Persson and Savulescu here argue that their proposal escapes his criticism because enhancements on the level of moral motivation could potentially help people to overcome their self-interest and their weakness of will, which is what ultimately drives the tragedy of the commons problem.

Christoph Bublitz also aims at claims by Savulescu and Persson. In "Saving the World through Sacrificing Liberties? A Critique of some Normative Arguments in Unfit for the Future", he analyses and dismisses their argument against a right to privacy. Furthermore, he argues for the more general point that an approach that explains problems such as climate change exclusively at the level of psychological deficits suffers from the shortcomings of methodological individualism. He argues that such an approach fails to account for higher-level and structural causes, such as the inherent dynamics of capitalism.

In their reply, "The Irrelevance of a Moral Right to Privacy for Biomedical Moral Enhancement", Persson and Savulescu defend their denial of a right to privacy against Bublitz' attack by, inter alia, drawing distinctions between legal and moral rights, as well as rendering their understanding of privacy and their argument against a moral right more precise. In addition, they counter the charge of methodological individualism by the more general claim that there are no "higher-level" social processes or structures that are independent of the minds of a large majority of the citizens.

John Danaher's article ("Why Internal Moral Enhancement Might Be Politically Better than External Moral Enhancement"), proposes drawing a distinction between "external" and "internal" means of improving morality. External means aim at enhancing moral behaviour through external cues and signals to make people behave in certain ways and to abstain from others. Internal means, by contrast, are alterations of brain processes that influence moral behaviour. Danaher argues that internal moral enhancement is likely to be preferable to external moral enhancement, especially when it comes to the legitimacy of political decisionmaking processes, because they are consciously perceived whereas external enhancements would bypass consciousness and, thus, reasoning capacities.

In their co-authored article ("Pow(d)er to the People? Voter Manipulation, Legitimacy, and the Relevance of Moral Psychology for Democratic Theory") the editors, Norbert Paulo and Christoph Bublitz, analyse the effect of manipulative state-run moral enhancement programmes on democratic legitimacy. They argue that a government cannot rule legitimately, from a democratic point of view, if it was elected by the very people it previously manipulated/enhanced, because conferring power from the governed onto the governors is a onedirectional relation. However, dilemmas between input legitimization and potentially catastrophic output run through major works in political philosophy and democratic theory. Moral enhancements thus actualize one of the central problems of democratic theory. 
Against the background of critique of substantial moral enhancements, Owen Schaefer and Julian Savulescu propose a form of moral enhancement that is not substantial but "formal", namely "Procedural Moral Enhancement". They suggest that it is rather uncontroversial to say that the enhancement of certain deliberative processes makes people more morally reliable. Drawing on the characteristics John Rawls proposed for "competent judges" [9], Schaefer and Savulescu suggest that the following capacities contribute to reliable moral decisions: logical competence, conceptual understanding, empirical competence, empathetic understanding, openness to revision, and bias avoidance.

One of the domains in which states exert particularly strong forms of power over citizens is the criminal justice system. In a paper that was perceived as provocative by some readers, Thomas Douglas [10] pondered over why criminal justice systems should be barred from intervening into offenders' minds with biomedical means ("neurocorrectives)". A main line in his argument asked why the state - and hence criminal justice systems - should not have a right to interfere with bodily integrity of offenders without consent given they already have the right to interfere with the liberties of offenders by imprisoning them. Is the right to bodily or mental integrity more "robust" than freedom of movement?

Douglas' paper is the target of the contributions by Gulzaar Barn and Elizabeth Shaw. Barn ("Can Medical Interventions Serve as 'Criminal Rehabilitation'?”) attacks two central elements of Douglas' argument. First, the parity claim, according to which there are no fundamental differences between incarcerations and interferences with bodily integrity, and the suggestion that the two can be justified on the same grounds. Second, by spelling out the implications of Douglas' position, Barn shows that it leads to unpalatable consequences. Together with further critical observations, this leads her to conclude that the imposition of medical correctives falls beyond the appropriate remit of the criminal justice system.

In her article ("The Right to Bodily Integrity and the Rehabilitation of Offenders Through Medical Interventions: A Reply to Thomas Douglas") Shaw critically engages with Douglas' challenge to the consent requirement and his robustness claim. She distinguishes different cases in which consent might be unnecessary (epidemics, children, dangerous activities) from punishment and rehabilitation and thereby casts doubts on some of
Douglas' premises. Furthermore, emphasizing harms and threats to individual agency, Shaw argues that the right to bodily integrity is indeed more robust than the rights pertaining freedom of movement, and that this should be the case.

Finally, Thomas Douglas responds to these criticisms ("Nonconsensual Neurocorrectives and Bodily Integrity: a Reply to Shaw and Barn"). He carefully engages with Shaw's different scenarios and with her arguments on harms and agency. He also carefully addresses Barn's reduction argument and other smaller points. Douglas' replies indicate that the exchanges have helped to move the debate forward.

Acknowledgements Several of the articles collected in this issue were presented and discussed at workshops on moral enhancement at MANCEPT, University of Manchester (2014), and at the University of Salzburg (2015). We wish to thank the Society for Applied Philosophy for the generous support of both workshops, and all authors for their very committed cooperation.

\section{References}

1. Rousseau, Jean-Jacques. 2002. The social contract: And, the first and second discourses. Edited and translated by Susan Dunn. New Haven: Yale University Press.

2. Aristotle. 2000. Aristotle: Nicomachean ethics. Translated by Roger Crisp. Cambridge, U.K. ; New York: Cambridge University Press.

3. Douglas, Thomas. 2008. Moral enhancement. Journal of Applied Philosophy 25 (3): 228-245.

4. Douglas, Thomas. 2015. The morality of moral neuroenhancement. In Handbook of Neuroethics, ed. Jens Clausen and Neil Levy, 1227-1249. Netherlands: Springer. https://doi.org/10.1007/978-94-007-4707-4_92.

5. DeGrazia, David. 2014. Moral enhancement, freedom, and what we (should) value in moral behaviour. Journal of Medical Ethics 40 (6): 361-368.

6. Persson, Ingmar, and Julian Savulescu. 2012. Moral enhancement, freedom and the god machine. The Monist 95 (3): 399-421.

7. Persson, Ingmar, and Julian Savulescu. 2013. Getting moral enhancement right: the desirability of moral bioenhancement. Bioethics 27 (3): 124-131.

8. Persson, Ingmar, and Julian Savulescu. 2014. Unfit for the future: The need for moral enhancement. Oxford: Oxford University Press.

9. Rawls, John. 1951. Outline of a decision procedure for ethics. Philosophical Review 60 (2): 177-197.

10. Douglas, Thomas. 2014. Criminal rehabilitation through medical intervention: moral liability and the right to bodily integrity. Journal of Ethics 18 (2): 101-122. 